\section{Correspondence on '2019 European League Against Rheumatism/American College of Rheumatology classification criteria for systemic lupus erythematosus' by Aringer et al}

The 2019 European League against rheumatism/American College of Rheumatology classification criteria (EULAR/ACR 2019 criteria) for systemic lupus erythematosus (SLE) has introduced a new scoring system to classify SLE. ${ }^{1}$ The EULAR/ ACR 2019 criteria include positive antinuclear antibody at least once as obligatory entry criterion; followed by additive weighted criteria grouped in seven clinical and three immunological domains and weighted from 2 to 10. Patients fulfilling at least one clinical criterion and accumulating $\geq 10$ points are classified. In validation cohort, a classification threshold score of $\geq 10$ yielded a sensitivity similar to that of the Systemic Lupus International Collaborating Clinics (SLICC) 2012 criteria $(96.1 \%$ vs $96.7 \%)$ and a specificity similar to that of the ACR 1997 criteria (93.4\% vs 93.4\%), demonstrating both excellent sensitivity and specificity. However, we have two concerns about its additive criteria and methodology.

First, some gastrointestinal injuries related to SLE, especially lupus enteritis, may be underestimated. Gastrointestinal symptoms are reported to occur in more than $50 \%$ of patients with SLE at some point in the course of their disease ${ }^{2}$ however, these symptoms are usually mild. ${ }^{3}$ Although lupus enteritis manifestations are non-specific (eg, abdominal pain, nausea, vomiting, anorexia and diarrhoea) and have wide range from mild to life-threatening (perforation and fistulisation), it has relatively specific features ('double-halo' and 'comb sign') on contrast-enhanced CT. ${ }^{4}$ The 'double-halo' (namely 'target sign') is a marker of abnormal bowel wall submucosal thickening, whereas the 'comb sign' correlates with mesenteric vessel prominence. ${ }^{4}$ However, the described abnormalities can also be seen in patients with pancreatitis, mechanical bowel obstruction, peritonitis or inflammatory bowel disease. ${ }^{5}$ Lupus enteritis mainly affects the small intestine; in rare circumstances, the colon and rectum can also be involved. ${ }^{6-12}$ Because of lack of radiology and endoscopy studies on the newly onset SLE, the actual incidence rate of lupus enteritis remains unknown. Recently, we encountered a case of severe lupus enteritis with multiple rectal ulcers and fistulisation formation (figure 1). This is a male patient in his $30 \mathrm{~s}$ who presented with severe diarrhoea, haematochezia and weight loss for 3 months. He had no dyspnoea, neuropsychiatric, musculoskeletal or mucocutaneous manifestations. Several days before admission, he had cough and low grade fever and this can be explained by mild community-acquired pneumonia and right-side pleural effusion confirmed by his chest CT. After admission, a transthoracic echocardiogram showed a slight pericardial effusion. Pleural or pericardial effusion can be explained by his hypoproteinemia, largely attributable to the protein-losing enteropathy caused by enteritis and rectal ulcers. Although the diagnosis of SLE was subsequently made according to his proteinuria $(1.09 \mathrm{~g} / 24$ hours), hypocomplementemia (C3: $0.2 \mathrm{~g} / \mathrm{L}, \mathrm{C} 4: 0.08 \mathrm{~g} / \mathrm{L})$ and SLE-specific antibody (anti-dsDNA antibody: $>800 \mathrm{IU} / \mathrm{mL}$ ), in terms of clinical domains in EULAR/ACR 2019 criteria, we felt lupus enteritis 'triumphing over' the seven orthodox clinical domains. Unfortunately, lupus enteritis has not yet been considered in ACR 1997 criteria, SLICC 2012 criteria or EULAR/ACR 2019. It is not even a candidate criteria in patients with early SLE, ${ }^{13}$
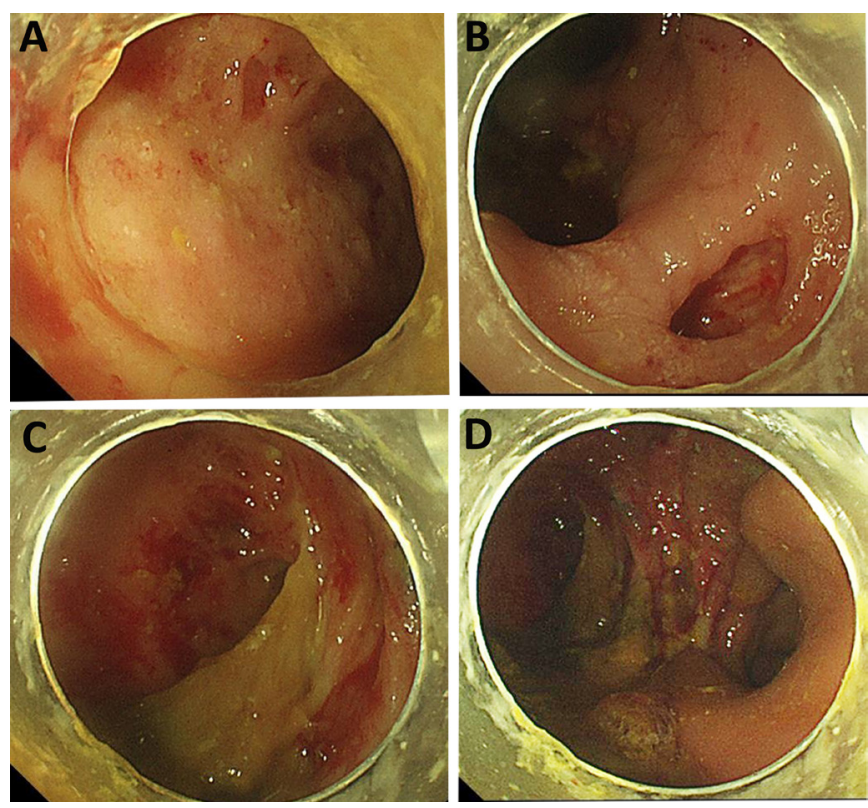

Figure 1 Endoscopic examination of the rectum. Multiple deep ulcers with mucosal friability, submucosal haemorrhage and purulent secretion $(A-C)$ and fistulisation (D) were observed. These endoscopic findings are not exactly the same as ulcerative colitis and Crohn's disease.

some of which subsequently being refined and constitute the EULAR/ACR 2019 criteria.

Second, rheumatologists should be informed of exact probability of illness in patients with underlying SLE who are below the threshold (ie, total score $<10$ ) so as to provide better decision-making, evaluation and follow-up. It is preferable to use logistic regression and nomogram to predict the probability. In addition, when patients have signs or symptoms suggestive of but not diagnostic of SLE, their physician must decide whether to (1) treat empirically, (2) not treat or (3) perform further diagnostic testing before deciding between options 1 and 2. Under this circumstance, decision-making based on the threshold of 10 generated by the receiver operating characteristics analysis seems risky, especially when clinical and immunologic parameters are ambiguous. Rheumatologists should also be informed of the net benefit ${ }^{14}$ from the patients when diagnosis is made and treatment is given at a threshold of 10 . This net benefit comparison should be suggested to carry out among ACR 1997 criteria, SLICC 2012 criteria, and EULAR/ACR 2019 criteria.

\section{Ran Cui $\odot,{ }^{1}$ Qian Wang, ${ }^{1}$ Hua Zhang, ${ }^{1}$ Shan $\mathrm{Wu}^{2}{ }^{2}$ Xin-Jian Wan, ${ }^{2}$ Sheng-Ming Dai ${ }^{1}$}

'Department of Rheumatology and Immunology, Shanghai Jiao Tong University Affiliated Sixth People's Hospital, Shanghai, China

${ }^{2}$ Department of Endoscopy, Shanghai Jiao Tong University Affiliated Sixth People's Hospital, Shanghai, China

Correspondence to Professor Sheng-Ming Dai, Department of Rheumatology and Immunology, Shanghai Jiao Tong University Affiliated Sixth People's Hospital, Shanghai 200233, China; shengmingdai@163.com

Contributors Concept and writing: RC and SMD; revising: SMD and XJW; acquisition of data: RC, QW, HZ, SW; analysis and interpretation of data: RC and SMD.

Funding The authors have not declared a specific grant for this research from any funding agency in the public, commercial or not-for-profit sectors.

Competing interests None declared. 
Patient and public involvement Patients and/or the public were involved in the design, or conduct, or reporting, or dissemination plans of this research. Refer to the Methods section for further details.

Patient consent for publication Obtained.

Provenance and peer review Not commissioned; internally peer reviewed.$$
\text { (2) }
$$$$
\text { OPEN ACCESS }
$$

Open access This is an open access article distributed in accordance with the Creative Commons Attribution Non Commercial (CC BY-NC 4.0) license, which permits others to distribute, remix, adapt, build upon this work non-commercially, and license their derivative works on different terms, provided the original work is properly cited, appropriate credit is given, any changes made indicated, and the use is non-commercial. See: http://creativecommons.org/licenses/by-nc/4.0/.

C Author(s) (or their employer(s)) 2020. Re-use permitted under CC BY-NC. No commercial re-use. See rights and permissions. Published by BMJ.

\section{Check for updates}

To cite Cui R, Wang Q, Zhang H, et al. Ann Rheum Dis Epub ahead of print: [please include Day Month Year]. doi:10.1136/annrheumdis-2020-218546

Received 9 July 2020

Accepted 11 July 2020

Ann Rheum Dis 2020;0:1-2. doi:10.1136/annrheumdis-2020-218546

ORCID iD

Ran Cui http://orcid.org/0000-0003-4923-5882

\section{REFERENCES}

1 Aringer M, Costenbader K, Daikh D, et al. 2019 European League against Rheumatism/American College of rheumatology classification criteria for systemic lupus erythematosus. Ann Rheum Dis 2019;78:1151-9.

2 Chng HH, Tan BE, Teh $\mathrm{CL}$, et al. Major gastrointestinal manifestations in lupus patients in Asia: lupus enteritis, intestinal pseudo-obstruction, and protein-losing gastroenteropathy. Lupus 2010;19:1404-13.

3 Li Z, Xu D, Wang Z, et al. Gastrointestinal system involvement in systemic lupus erythematosus. Lupus 2017;26:1127-38.

4 Kröner PT, Tolaymat OA, Bowman AW, et al. Gastrointestinal manifestations of Rheumatological diseases. Am J Gastroenterol 2019;114:1441-54.

5 Janssens P. Arnaud L, Galicier L, et al. Lupus enteritis: from clinical findings to therapeutic management. Orphanet J Rare Dis 2013;8:67.

6 Yau AHL, Chu K, Yang HM, et al. Rectal ulcers induced by systemic lupus erythematosus. BMJ Case Rep 2014;2014:bcr2014205776.

7 Yuasa S, Suwa A, Hirakata M, et al. A case of systemic lupus erythematosus presenting with rectal ulcers as the initial clinical manifestation of disease. Clin Exp Rheumatol 2002;20:407-10

8 Teramoto J, Takahashi Y, Katsuki S, et al. Systemic lupus erythematosus with a giant rectal ulcer and perforation. Intern Med 1999;38:643-9.

9 Chattopadhyay P, Abby Philips C, Dhua D, et al. Systemic lupus erythematosus presenting as ischaemic proctitis. Lupus 2011;20:653-5.

10 Mansoor AC, Jemshad A, Musambil M. Systemic lupus erythematosus presenting as rectal ulcer and longitudinal myelopathy. Int J Rheum Dis 2017;20:1818-20.

11 Kaieda S, Kobayashi T, Moroki M, et al. Successful treatment of rectal ulcers in a patient with systemic lupus erythematosus using corticosteroids and tacrolimus. Mod Rheumatol 2014;24:357-60.

12 Lee J-R, Paik C-N, Kim J-D, et al. Ischemic colitis associated with intestinal vasculitis: histological proof in systemic lupus erythematosus. World I Gastroenterol 2008:14:3591-3.

13 Tedeschi SK, Johnson SR, Boumpas D, et al. Developing and refining new candidate criteria for systemic lupus erythematosus classification: an international collaboration. Arthritis Care Res 2018;70:571-81.

14 Vickers AJ, Elkin EB. Decision curve analysis: a novel method for evaluating prediction models. Med Decis Making 2006;26:565-74. 